Blommaert, Jan - Backus, Ad 2012: Superdiverse repertoires and the individual. - Tilburg Papers in Culture Studies 24 s. 1-32. https://www.tilburguniversity. edu/research/institutes-and-researchgroups/babylon/tpcs/download-tpcspaper-24.pdf.htm (15.4.2019).

Coulmas, Florian 2018: An introduction to multilingualism. Language in a changing world. Oxford Textbooks in Linguistics. Oxford: Oxford University Press.

Gee, James Paul 1999: An introduction to discourse analysis. London: Routledge.
Sanada, Shinji - Shōji, Hiroshi (toim.) 2005: Nihon no tagengo shakai [Japanin monikielinen yhteiskunta]. Tokio: Iwanami Shoten.

Tagengoka genshō kenkyūkai [Monikielistymisen tutkimusseura] (toim.) 2013: Tagengo shakai nihon. Sono genjō to kadai [Japani monikielisenä yhteiskuntana. Nykytilanne ja tutkimuskysymykset]. Tokio: Sangensha.

Vertovec, Steven 2007: Super-diversity and its implications. - Ethnic and Racial Studies 30 s. 1024-1054. https://doi. org/10.108o/01419870701599465.

\title{
Pohjoisgermaanin ja itämerensuomen äännehistoriallisten ilmiöiden selityksiä täydentävä väitöstutkimus
}

\author{
Johan Schalin: Preliterary Scandinavian \\ sound change viewed from the east. \\ Umlaut remodelled and language contact \\ revisited. Nordica Helsingiensia 54. \\ Helsinki: Helsingin yliopisto 2018. $411 \mathrm{~s}$. \\ ISBN 978-951-51-4387-7.
}

Teologian maisteri Johan Schalin väitteli yllä mainittua nimeä kantavalla artikkeliväitöskirjalla pohjoismaisten kielten oppiaineessa Helsingin yliopistossa syyskuussa 2018. Schalinin väitöskirja käsittelee ensisijaisesti skandinaavisten kielten äännehistoriaa ja kielikontakteja itämerensuomalaisiin kieliin 200-luvulta jKr. 1200 -luvulle jKr. (s. 5). Täten väitöskirjalla on relevanssia myös (itämeren-) suomen varhaishistorian tutkimukselle. Väitöskirja koostuu viidestä tutkimusartikkelista sekä yhteenveto-osiosta. Yksi tutkimusartikkeleista on yhteisjulkaisu folkloristi, dosentti Frogin kanssa. Väitös- kirja on enimmäkseen englanninkielinen, mutta siihen sisältyy yksi ruotsinkielinen artikkeli, laaja ruotsinkielinen tiivistelmä sekä lyhyt suomenkielinen tiivistelmä. Kantaskandinaavin ja jossain määrin kantasuomen äännehistoriaa käsittelevän väitöskirjan kielivalintoja voinee pitää perusteltuina, sillä suomalaisen tiedeyhteisön ruotsin kielen taito on vaihteleva ja skandinaavisessa tiedeyhteisössä suomen kielen taito on harvinainen.

Kantaskandinaavista (n. 100-700 jKr.) on omaksuttu lukuisia lainasanoja itämerensuomeen ja saameen, ja lisäksi se on jättänyt jälkeensä myös suoria kielenmuistomerkkejä erilaisiin materiaaleihin kaiverrettujen riimukirjoitusten muodossa. Kyse ei siis ole likimainkaan vain rekonstruoidusta kielimuodosta. Asiaa tuntematon lukija saattaa kuitenkin saada vastakkaisen käsityksen väitöskirjan nimen ensimmäisestä sanasta preliterary. 
Tekijä on tiedostanut asian (s. 46) ja perustelee sananvalintaansa riimukirjoitusten "epätavallisella ja fragmentaarisella genrellä" ja "ortografisella epäluotettavuudella".

Schalinin väitöskirjan rungon muodostavat kokoomateoksissa ja tieteellisissä aikakauslehdissä julkaistut tutkimusartikkelit. Kolmessa niistä painottuvat kielikontaktit (ks. Schalin 2014; Schalin \& Frog 2014; Schalin 2016) ja lopuissa historiallisen fonologian teoria (ks. Schalin 2017a, 2017b).

Yhteenveto-osiota voi pitää artikkeliväitöskirjan keskeisimpänä osana, sillä se tekee yleensä eri aikaan ilmestyneistä ja ainakin jossain määrin eri aihepiirejä käsittelevistä artikkeleista väitöskirjan. Yhteenveto on väittelijän "viimeinen sana", jota kirjoittaessaan hän ei useinkaan enää ajattele kaikesta samoin kuin ensimmäisessä artikkelissaan. Näin on asianlaita myös arvioitavassa työssä, mikä ilmenee jo sen esipuheesta ja ruotsinkielisestä tiivistelmästä (s. 15; ks. myös esim. s. 55). Edellä mainituista syistä keskityn seuraavassa Schalinin väitöskirjan yhteenveto-osion arviointiin. Kaiken kaikkiaan 168 sivua käsittävässä yhteenvedossa käydään lävitse väitöskirja-artikkelien keskeinen sisältö jossain määrin päivitetysti. Osioon sisältyvät myös Errata and corrigenda -luettelot, joissa oikaistaan artikkeleissa havaittuja virheitä.

\section{Äännehistorian kysymysten arviointia}

Schalinin väitöskirjan keskiössä oleva äännehistoria on historiallisen kielitieteen ydinaluetta. Koska Schalinin väitöskirjan nimi indikoi pohjoisgermaanisen umlautin eli vokaalistoa koskevan (osittaisen) regressiivisen (etä)assimilaation (esim. gastiz > gestr 'vieras') olevan väitöskirjan pääasiallinen tutkimuskohde, tarkastelen ensimmäiseksi umlautia koskevia tuloksia.
Äännehistoriallisen selityksen taloudellisuus on eräs Schalinin eksplikoimista keskeisistä lähtökohdista (ks. esim. s. 84, $86,103)$, jos kohta hän myös rekonstruoi kantaskandinaavin vokaalistoon yhden uuden äänteen (ks. alla). Hän tähdentää empiirisen evidenssin tarkan analyysin tärkeyttä mutta nojaa argumentaatiossaan vahvasti myös B. Elan Dresherin (mm. 2009) foneettisiin teorioihin (esim. s. 46). Schalin pyrkii ratkaisemaan pääpiirteiltään hyvin tunnetun umlaut-ilmiön moniin yksityiskohtiin liittyvät anomaliat postuloimalla painollisten ja painottomien tavujen $i$-vokaalin pariksi takaisemman, todentamattoman $\dot{i}$-äänteen. Tällä hän pyrkii ratkaisemaan sen, reaalistuiko umlaut vai ei (s. 6, 103, 121-122). Rekonstruoimansa ${ }^{\star} i$ :n synnyn Schalin olettaa muinaisgermaanisen äänteenmuutoksen $e>i$ aiheuttamaksi ketjusiirtymäksi. Schalinin mielenkiintoista hypoteesia ei ehkä koskaan kyetä sitovasti verifioimaan eikä falsifioimaan käytettävissämme olevan todistusaineiston riittämättömyyden vuoksi.

Toinen Schalinin väitöskirjan keskeinen uusi hypoteesi koskee kantaskandinaavin rotasismia. Kantaskandinaavissa tapahtui todistettavasti äännekehitys $[\mathrm{z}]>>[\mathrm{r}]$, jossa /s/:n allofoni $[\mathrm{z}]$ lankesi yhteen kielessä jo entuudestaan olemassa olleen /r/:n kanssa ja jonka väliasteeksi nordistit ovat kauan olettaneet grafeemilla $R$ merkityn palataalisen $r$-äänteen. Schalin kyseenalaistaa (s. 3) oletetun palataalisen $r$-äänteen esiintymisen ja rekonstruoi sen tilalle laminaalisen frikatiivin (s. 146-147). Schalin voi olla oikeilla jäljillä; muistettakoon, että rotasismi $z>r$ tapahtui myös länsigermaanissa.

Schalinin väitöskirjassa on selviä ansioita, joista lisää tuonnempana, mutta myös kritiikkiä ansaitsevia piirteitä. Sivulla 70 Schalin katsoo voivansa sivuuttaa väitöskirjassani (Heikkilä 2014) esittämäni äänteenmuutosten kronologiat, koska olen siinä päätynyt sellaisiin johto- 
päätöksiin kuin että äänteenmuutos $\mathrm{X}$ on tapahtunut myöhemmin kuin äänteenmuutos A mutta aiemmin kuin B. Juuri niin äännehistorian kronologiaa kuitenkin rakennetaan synkronisesta kieliaineistosta, ja niin on Schalinkin väitöskirjassaan tehnyt (ks. esim. s. 67, 86, 143144). Hän perustelee irtiottoaan myös väittämällä (s. 70), että käsitykseni äänteenmuutosten ontologiasta olisi se, että ne ovat poikkeuksetta välittömiä atomistisia tapahtumia. Niin en ole kuitenkaan väittänyt (ks. Heikkilä 2014, esim. 95-96). ${ }^{1}$ Toisaalla Schalin toteaa avoimesti (esim. s. 121) oman tutkimuksensa vaaroina olevan samat metodologiset sudenkuopat kuin muidenkin tutkijoiden. Huomattakoon vielä, että Schalinin (esim. s. 53, 67) omat ajoitusehdotukset kantaskandinaavin ja myöhäiskantasuomen äänteenmuutoksille eivät useinkaan sanottavasti poikkea omistani (ks. Heikkilä 2011: 68-74, 2014: 97-101, 125-127). Sivulla 67 Schalinin argumentaatio päätyy itse asiassa Kallion (2014: 163-164) kautta omiin ajoituksiini.

Schalin otaksuu, että umlautin esiaste esiintyi foneettisena ilmiönä jo vähintään länsi- ja pohjoisgermaanissa - siis viimeistään aivan ajanlaskun alussa (s. 3132). Näin Schalin lähestyy Kalevi Wiikin (ks. jo 1989) teoriaa kantagermaanissa idullaan olleesta umlaut-ilmiöstä. Vaikka Wiikin uralilaisten kielten kantakielivaiheille antamat ajoitukset ovat nykytiedon valossa aivan liian varhaisia eikä uralilaisesta substraatista (esi)kantagermaanissa ole tieteellisesti vakuuttavia todisteita, Wiikin selityksessä esimer-

1. Jos ruotsinkielinen Schalin olisi lukenut ruotsinkielisen väitöskirjani huolellisemmin, hän olisi myös huomannut, että hänen (s. 98, 132) referoimansa Janne Saarikiven (2015: 105) kritiikki väitöskirjastani on korttitalo. Ruotsinkielinen lyhenne e.Kr. on suomeksi jKr. Siksi "andra hälften av 400-talet e.Kr." (Heikkilä 2014: 260) ei ole "400 $B C^{\prime \prime}$ kuten Saarikivi (mp.) mm. virheellisesti väittää. kiksi kantagermaaniselle äänteensiirrokselle lienee varteenotettavia foneettisia yksityiskohtia (ks. Heikkilä 2014: 43-54).

Kaikkien historioivien tieteenalojen - kielitieteestä geologiaan ja arkeologiasta paleontologiaan - haasteena on nykyhetkessä olevan todistusaineiston avulla selvittää menneisyyden tapahtumien keskinäinen aikajärjestys ja ajallinen etäisyys nykyhetkestä ja toisistaan. Kronologia iänmäärityksineen on siten aina rakennelma, ja kaukaista menneisyyttä tutkivien tieteenalojen useimmat tulokset ovat eriasteisia todennäköisyyksiä. Esimerkiksi kahden äänteenmuutoksen keskinäisestä ikäjärjestyksestä ajassa ja paikassa on kyllä olemassa totuus, mutta sen tavoittaminen jää usein todistusaineiston niukkuuden tai suoranaisen puutteen takia suuremman tai pienemmän todennäköisyyden asteelle. Monen tieteenalan hallitseva teoria vallitsee (ja kaatuu) juuri kronologisen tietämyksen myötä.

Yhteenveto-osion lähdeluettelosta puuttuvat käytetyt etymologiset sanakirjalähteet, esimerkiksi LägLoS (= Lexikon der älteren germanichen Lehnwörter in den ostseefinnischen Sprachen) ja VAEO (= Våre arveord: etymologisk ordbok), mutta ne on mainittu lyhenteiden yhteydessä. Viime kädessä runologian tuloksiin (so. riimukirjoitusten tulkintaan ja ajoitukseen) pohjautuvan väitöstutkimuksen yhteenveto-osiossa olisi olettanut viitattavan myös Samnordisk runtextdatabas -tietokantaan.

Arvioitavan väitöskirjan kieliasu on virheetön lukuun ottamatta joitakin pieniä kirjoitusvirheitä kuten fomer allophones (s. 70) ja christmas (s. 84). "Kristusmessusta" eli joulusta puheen ollen ensin pakanallista talvijuhlaa ja sittemmin kristillistä Jeesuksen syntymäjuhlaa merkitsevän yleisgermaanisen sanan kantagermaaniseksi väitetty rekonstruktio ${ }^{*}$ jeulo $($ s. 34,84$)$ on positiivisen empiirisen evidenssin valossa virheellinen (po. $\left.{ }^{\star} j e \gamma w l \bar{o}<{ }^{\star} j e \chi w l \bar{o}\right)$. Mainittakoon 
vielä, että sana joulu (< kantaskandinaavin ${ }^{\star}$ jeulu $<$ kgerm. ${ }^{\star} j e \gamma w l \bar{l}<{ }^{\star} j e x w l \bar{o}$; esim. Hirvonen 1997) todistaa omalta osaltaan äänneasullaan, että sanansisäinen $\chi$ katosi kantaskandinaavista ennen sananalkuisen $j$ :n katoa (vrt. Heikkilä 2014: 126, 131). Sivulla 98 Schalin kirjoittaa kuin Abborrfors eli Ahvenkoski olisi Ankkapurha eli Anjalankoski, vaikka niiden tarkoitteet sijaitsevat linnuntietäkin pitkin kuljettuna kolmenkymmenen kilometrin päässä toisistaan. Tämä käy ilmi esimerkiksi Karttapaikka-palvelusta (ks. https://www.maanmittauslaitos.fi/karttapaikka).

\section{Kokoavaa arviointia}

Schalinin väitöskirjan selvimmät ansiot ovat nähdäkseni kantaskandinaavisten äänteenmuutosten rekonstruoinnin ja mallinnuksen teoreettinen edelleenkehittäminen, teorian implementointi tutkimuskohteeseen ja kantaskandinaavin oletetun palataalisen $r$-äänteen esiintymisen perusteltu kyseenalaistaminen. Väitöskirjassa esitetyt kantaskandinaavin ja kantasuomen relatiiviset ja absoluuttiset kronologiat eivät sen sijaan sanottavasti poikkea viimeaikaisen suomalaisen ja skandinaavisen tutkimuksen tuloksista. Ennemminkin Schalinin väitöskirja vahvistaa niitä; kantaskandinaavinen kielivaihe tarkempine alajakoineen ajoittuu erittäin suurella todennäköisyydellä ensimmäiselle vuosituhannelle ajanlaskun alun jälkeen ja sekä itämerensuomen kantamuoto kantasuomi että saamelaiskielten kantamuoto kantasaame hyvin todennäköisesti kokonaisuudessaan Pohjolan rautakauteen (n. 700 eKr. - 1200 jKr.). Suomen kielen napakairan kaltaiset äänneasunsa verrattain vanhoiksi osoittamat suppealevikkiset lainasanat viittaavat siihen, että itämerensuomea oli alettu 500-lukuun ¡Kr. mennessä puhua laajalla alueella - myös Suomenlahden pohjoispuolella (ks. esim. SSA s.v. napakaira; Heikkilä 2011, 2014) -, jos kohta viimeiset täysin tai melkein yhteisitämerensuomalaiset äänteenmuutokset $\left({ }^{*} \check{s}>h\right.$ ja ${ }^{\star} z>h$ sekä $c>s$; Kallio 2007, 2014) lienevät tapahtuneet vasta jonkin verran ajanlaskun alun jälkeen (Heikkilä 2014: 41-132).

Kokonaisuutena tarkasteltuna Schalinin väitöskirja antaa aihetta kahtalaiseen vaikutelmaan. Väitöskirjan tekijä on fonetiikan ja kantaskandinaavin historiallisen fonologian teorian tuntija, jonka tutkimus on kontribuutio nordistiikalle ja fennistiikalle, mutta paikoittaiset epätarkkuudet ja virheet aiemman tutkimuskirjallisuuden referoinnissa eivät lisää väitöskirjan arvoa.

Palaan lopuksi vielä väitöskirjan esipuheeseen, jossa Schalin ottaa esille tutkimusrahoituksen saamisen vaikeuden. Mietin, mikä on suomalaisen tiedeyhteisön vointi kymmenen vuotta uuden yliopistolain voimaantulon jälkeen, aikana, jolloin humanistiset tieteet eivät ole trendikkäitä ja taloudelliset resurssit ovat moniaalla olleet kauan niukkoja.

\section{MIKKO HEIKKILÄ etunimi.k.sukunimi@tuni.fi}

Kirjoittaja on Tampereen yliopiston monitieteisen diakronisen kielentutkimuksen dosentti.

\section{Lähteet}

Dresher, B. ElAN 2009: The contrastive hierarchy in phonology. Cambridge: Cambridge University Press.

Heiккilä, Mıкко 2011: Huomioita kantasaamen ajoittamisesta ja paikantamisesta sekä germaanisia etymologioita saamelais-suomalaisille sanoille. - Virittäjä 115 s. 68-84.

— 2014: Bidrag till Fennoskandiens språkliga förhistoria i tid och rum. Helsingfors: Helsingfors universitet. http://urn.fi/ URN:ISBN:978-951-51-0066-5.

Hirvonen, Ilkka 1997: Mikä on sanojen 
juhla ja joulu germaanis-skandinaavinen alkuperä? - Sananjalka 39 s. 55-64.

Kallio, Petri 2007: Kantasuomen konsonanttihistoriaa. - Jussi Ylikoski \& Ante Aikio (toim.), Sámit, sánit, sátnehámit. Riepmočála Pekka Sammallahtii miessemánu 21. beaivve 2007 s. 229-249. Suomalais-Ugrilaisen Seuran Toimituksia 253. Helsinki: Suomalais-Ugrilainen seura.

- 2014: The Diversification of ProtoFinnic. - Joonas Ahola, Frog \& Clive Tolley (toim.), Fibula, fabula, fact. The Viking age in Finland s. 155-168. Studia Fennica Historica 18. Helsinki: SKS.

SAARIKIVI, JANne 2015: REVIEW. - Nordic Journal of Linguistics 38 s. 100-107.

Samnordisk runtextdatabas. Uppsala universitet. https://www.nordiska.uu.se/forskn/ samnord.htm (11.1.2019).

SCHALIN, JohaN 2014: ScandinavianFinnish language contact in the Viking age in the light of borrowed names. - Joonas Ahola, Frog \& Clive Tolley (toim.), Fibula, fabula, fact. The Viking age in Finland, s. 399-436. Helsinki: SKS.

_ 2016: Östskandinavisk utveckling av den urnordiska $a i$-diftongen och palatalt $r$ i ljuset av finska ljudsubstitutioner. -
D. Andersson, L.-E. Edlund, S. Haugen, \& A. Westum (toim.), Studier i svensk språkhistoria 13. Historia och språkhistoria s. 241-262. Umeå: Institutionen för språkstudier, Umeå universitet \& Kungl. Skytteanska Samfundet.

2017a: Scandinavian front umlaut revisited and revised. - Arkiv för nordisk filologi 132 s. 5-74.

2017b: Scandinavian umlaut and contrastive feature hierarchies. - NorthWestern European Language Evolution (NOWELE) 70 s. 171-254.

Schalin, Johan \& Frog 2014: Toponymy and seafaring. Indications and implications of navigation along the Åland islands. - Joonas Ahola, Frog \& Jenni Lucenius (toim.), The Viking age in Åland. Insights into identity and remnants of culture s. 273-302. Helsinki: Finnish Academy of Science and Letters. SKS $=$ Suomalaisen Kirjallisuuden Seura.

SSA = Suomen sanojen alkuperä. Etymologinen sanakirja. $2 L-P$. Helsinki: Suomalaisen Kirjallisuuden Seura \& Kotimaisten kielten tutkimuskeskus 1995.

WIIK, KALEVI 1989: Ikivanha kuuntelutesti. Ääntäjinä kantagermaanit, kuuntelijoina kantasuomalaiset. Turku: Turun yliopisto.

\section{Vuorovaikutuslingvistiikan jättiläinen}

\section{Elizabeth Couper-Kuhlen \& Margret Selting: Interactional linguistics. Studying language in social interaction. Cambridge University Press 2018. 617 s. + verkkoliit- teet 291 s. ISBN 978-1-107-61603-5. Verkkoliit- teet ovat luettavissa osoitteessa http:// www.cambridge.org/interactional.}

Keskustelunanalyysin, antropologisen lingvistiikan sekä kieltä funktionaalisesta ja kontekstin huomioivasta näkökulmasta tarkastelevien kielitieteellisten suuntausten rajapinnassa syntynyt vuorovaikutuslingvistiikka (interactional linguistics) on parinkymmenen viime vuoden aikana kehittynyt omaksi tutkimussuuntauksekseen, jossa kieltä ja sen rakenteita tarkastellaan osana sosiaalista vuorovaikutusta. Alan tutkimusta tehdään eri puolilla maailmaa ja monien kielten parissa. Tätä 